Federal Reserve Bank of Minneapolis

Quarterly Review

Fall 1980

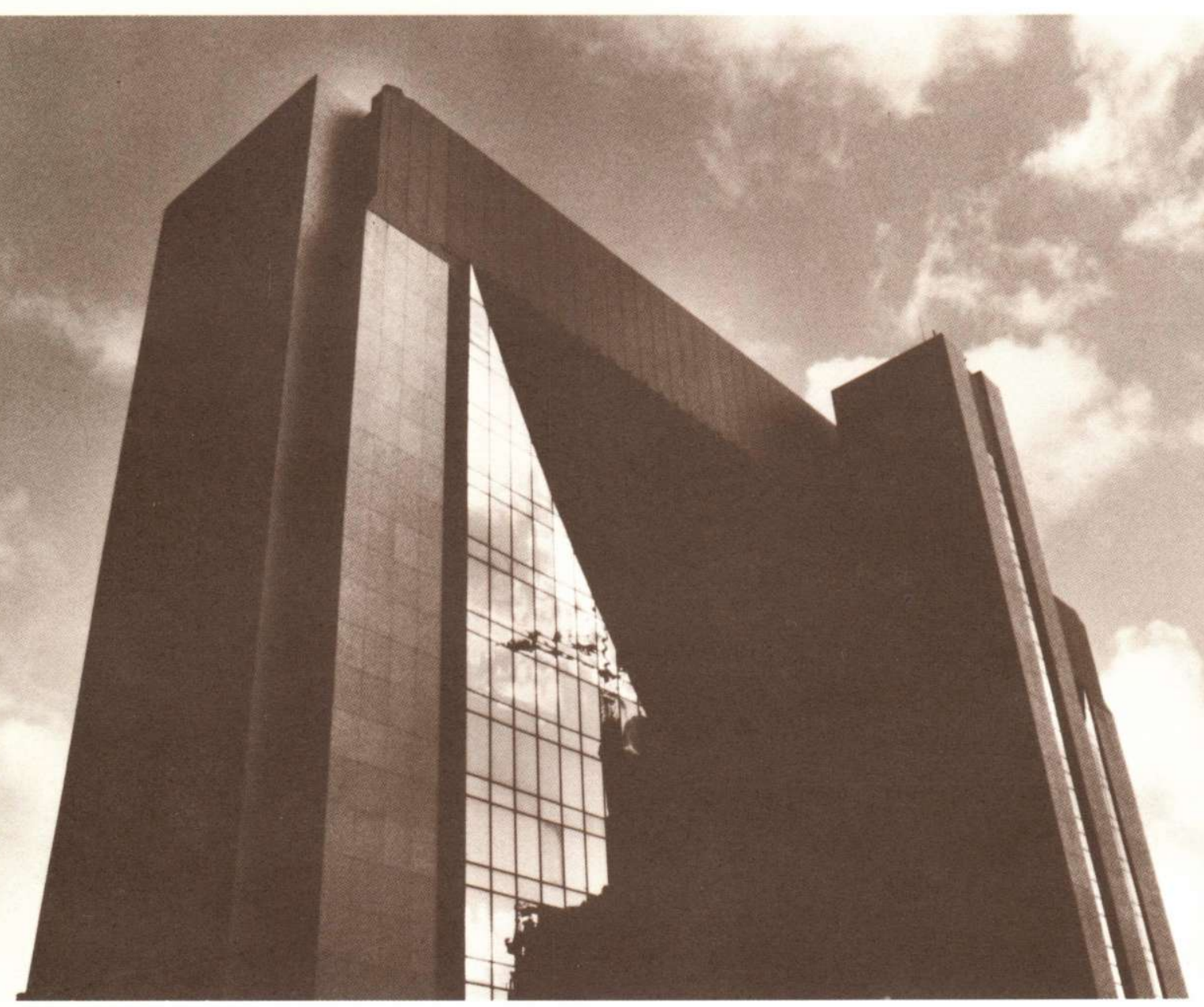

A New Approach to Monetary Control (p. 1)

Supply-Side Tax Cuts:

Will They Reduce Inflation? (p. 6)

Integrating Micro and Macroeconomics: An Application to Credit Controls (p. 16)

District Conditions (p. 30) 
Federal Reserve Bank of Minneapolis Quarterly Review vol. 4, No. 4

This publication primarily presents economic research aimed at improving policymaking by the Federal Reserve System and other governmental authorities.

Produced in the Research Department. Edited by Arthur J. Rolnick, Kathleen S. Rolfe, and Alan Struthers, Jr. Graphic design and charts drawn by Phil Swenson, Graphic Services Department.

Address requests for additional copies to the Research Department,

Federal Reserve Bank, Minneapolis, Minnesota 55480.

Articles may be reprinted if the source is credited and the Research

Department is provided with copies of reprints.

The views expressed herein are those of the authors and not necessarily those of the Federal Reserve Bank of Minneapolis or the Federal Reserve System. 


\section{Supply-Side Tax Cuts: Will They Reduce Inflation?}

Thomas M. Supel, Senior Economist

Research Department

Federal Reserve Bank of Minneapolis

There is wide agreement that the fiscal policy that has resulted in successive and large budget deficits in the United States could be modified to play a more constructive role in shaping our overall economic performance, but there is much disagreement as to precisely how to modify it. One point of view on this issue is that of supply-side economics, which stresses that in order to enhance economic performance, fiscal policy needs to take account of incentives to save, invest, and work. By taking advantage of these incentives, according to supply-side advocates, properly constructed tax cuts could increase productivity and thereby help offset inflationary pressures in the economy.

This conclusion - while having considerable intuitive appeal - is, in fact, open to question on at least two grounds. First, it is based partly on economic models that are seriously flawed. Supply-side models are traditional macroeconomic models that have been reworked to reflect the supply-side thinking on incentives, productivity, and inflation. Supply-side models may be improvements over the earlier models for purposes of forecasting under a given historical policy. But they have not solved the major problem of the traditional models they were designed to replace: they are still incapable of assessing the effects of a change in policy by simulating alternative policy actions. The conclusion that tax cuts can increase productivity and thereby reduce inflation is questionable, secondly, because the relationship between productivity and inflation is much less certain than many supply-side advocates acknowledge. The empirical evidence suggests that this relationship is extremely tenuous. My point is not that fiscal or tax policy should stay the same-in fact, a tax cut that is balanced by an expenditure cut may be warranted - but that some of the key arguments that the supply-side advocates use to justify cutting taxes alone or cutting taxes more than expenditures are not supported by the evidence.

\section{Defects of Traditional Models}

Supply-side models are attempts to correct the defects of traditional models and thus produce better assessments of the effects of alternative policies. They were developed after the traditional models repeatedly and spectacularly failed to produce accurate assessments of the policies that were begun in the 1970s.

The traditional models, based on Keynesian macroeconomics, seemed to be working well in the 1960s. They appeared to be able to explain the relationship between inflation and unemployment that had been observed in the United States and other countries during the 1960 s, a relationship shown in Chart 1 . In general, these models interpreted this relationship as a trade-off or a menu of choices, implying that policymakers could reduce unemployment by accepting a little more inflation. In 1964, the models' implications were put to the test: taxes were cut in an attempt to reduce unemployment. In this case, the economy appeared to behave as the models said it would. Inflation did not increase very much, but unemployment dropped sharply from roughly 5.5 percent in 1963 to nearly 4 percent in 1965. The traditional models thus gained respect in academia and in Congress.

In the 1970s, however, the models' predictions were so far from the mark that they were difficult to take 
seriously anymore. The problem was not just that prices were rising faster than the models had predicted at any given unemployment rate. It was that, in addition, unemployment was going up along with prices, as seen in Chart 1, a state of affairs which the traditional models could not explain without incorporating factors that were originally outside the model. With inflation and unemployment rising together, it was clear that the traditional models were defective, and economists began to alter them to make them conform better to the facts.

\section{Supply-Side Models: Considering Incentives}

Some economists believed that the principal defect of the traditional models was that they ignored incentives to work, save, and invest, incentives that affect people's decisions to produce goods and services and thus affect the supply side of the economy. An adverse shift in supply could indeed explain the adverse shift in the relationship between unemployment and inflation. So

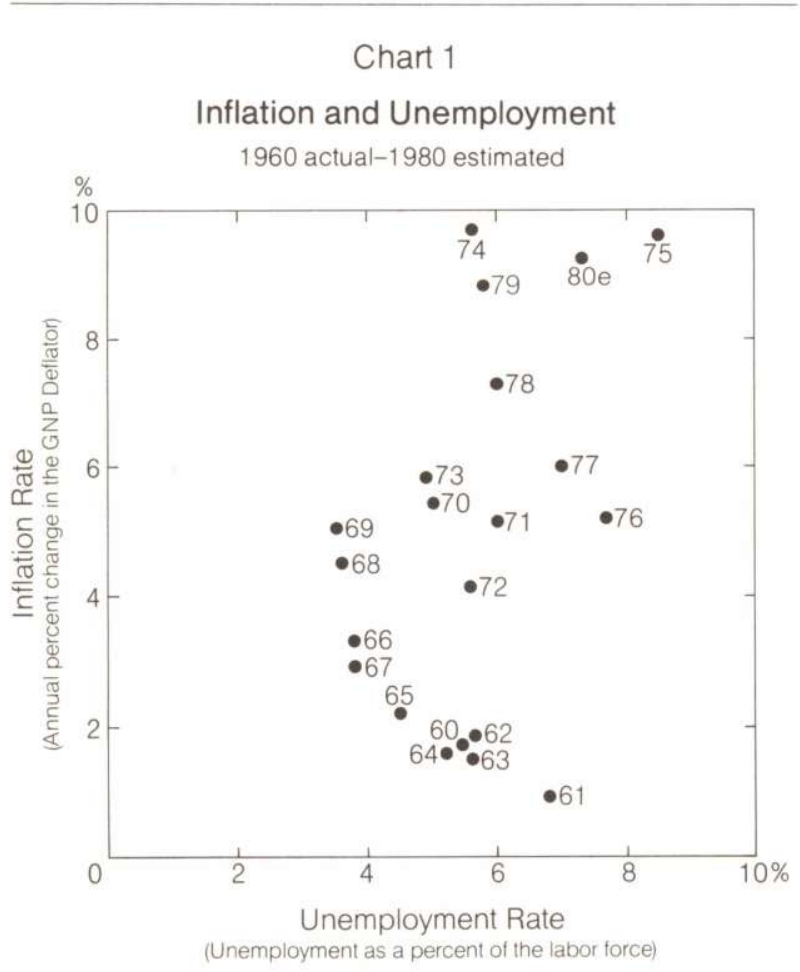

Source: U.S. Department of Commerce economists devised ways to incorporate such incentives into the traditional models. They did this, specifically, by adding policy variables (such as variables that incorporate the rate of taxation) to versions of the equations that appeared in the older models, so that a change in taxes would lead directly to a change in consumption and labor supply.

For example, in the 1972 version of the Wharton model (McCarthy 1972), a well-known traditional model, one of the equations that represents how economic agents decide to consume (that is, the consumption decision rule) is basically constructed this way:

$$
\begin{aligned}
& \text { Consumption of nondurable goods } \\
& \text { depends on } \\
& \text { - past consumption } \\
& \text { - disposable income } \\
& \text { - the price of nondurable goods } \\
& \text { relative to other consumer goods. }
\end{aligned}
$$

This equation, of course, is greatly simplified here, but it is detailed enough to illustrate the evolution to supply-side models. In the 1980 version of the Evans model (Evans Economics 1980), which is representative of supply-side models, the equation for consumption is similar, except for the addition of one policyspecific term:

$$
\begin{aligned}
& \text { Consumption of nondurable goods } \\
& \text { depends on } \\
& \text { - past disposable income } \\
& \text { - the price of nondurable goods } \\
& \text { relative to other consumer goods } \\
& \text { - the real after-tax rate. }
\end{aligned}
$$

In both models, a tax cut encourages consumption by increasing disposable income. In the Evans model, though, a tax cut also has an opposing effect - it discourages consumption by increasing the real after-tax interest rate and thereby encouraging saving. ${ }^{1}$ The real after-tax interest rate, presumably, was added to represent the direct incentive to save instead of to consume when taxes on income are reduced. Without actually simulating the model, it is impossible to tell if the effects of the the real after-tax interest rate outweigh the effects of disposable income. Nevertheless, the Evans model

\footnotetext{
1 Most economic researchers have been unable to show a clear direction to the impact of a change in the interest rate on the consumption-saving decision of the consumer. Boskin (1978), however, found that an increase in the real after-tax rate of return leads to an increase in saving. The Evans model is consistent with this work.
} 
does take into account some incentives to save instead of to consume that were not explicitly considered in the traditional Wharton model.

In the equation that determines the labor supply, the Evans model also attempts to improve on traditional models, such as the Wharton model, by adding terms that take account of incentives. In the Wharton model, as in most traditional models, the amount of labor supplied is determined by labor demand - that is, there is no decision rule for the supply of labor. In the only equation related to the supply of labor,

$$
\begin{aligned}
& \text { The civilian labor force } \\
& \text { depends on } \\
& \text { - civilian employment } \\
& \text { - lagged unemployment. }
\end{aligned}
$$

The term lagged unemployment means that a previous unemployment rate or an average of several previous rates has been used.

In the Evans supply-side model, labor supply is expressed as a decision rule. It is disaggregated into age-sex groups, and a typical decision rule is that

$$
\begin{aligned}
& \text { The labor force participation rate } \\
& \text { for females ages } 25-54 \\
& \text { depends on } \\
& \text { - lagged inflation } \\
& \text { - lagged unemployment } \\
& \text { - the real after-tax wage rate. }
\end{aligned}
$$

This is a decision rule because it contains variables that are relevant to the labor-supply decisions of optimizing consumers. For our purposes, the most significant variable is the real after-tax wage rate, which is supposed to capture how incentives to work affect labor supply. In the Wharton model a cut in the wage tax does not directly affect labor supply because it does not determine either employment or unemployment. In the Evans model, however, a cut in the wage tax increases labor supply by increasing the real after-tax wage rate - that is, by increasing take-home pay. In future periods it increases it further by decreasing unemployment and, perhaps, inflation.

The consumption and labor-supply equations contain the major differences between the Wharton and Evans models. Given the supply-side emphasis on the investment decision, one might also expect to find that the investment equation of the new models also differs in important ways from that of the old models. This, however, does not seem to be the case. The fiscal parameters included in the new supply-side models, such as the corporate tax rate and the investment tax credit, have been integral parts of traditional models, at least as far back as the 1972 Wharton model.

The differences between the consumption and laborsupply equations in the Wharton and Evans models imply that a tax cut in a supply-side model should increase consumption less and increase the labor supply more than in traditional models. A larger share of output, therefore, is potentially available for capital investment. Increasing investment leads, over time, to a larger capital stock and allows producers to have better tools and technology, so that productivity (output per worker) increases. Thanks to the increased productivity and the increased labor force, a tax cut in a supply-side model eventually leads to a greater increase in goods and services than a tax cut would in a traditional model. In fact, the output effect in the supply-side model may be so large that the rate of inflation falls. Traditional models, in contrast, always show a tax cut increasing inflation. In short, the supply-side argument is lower taxes, higher productivity, and possibly lower inflation.

It is important to note that the supply-side argument for a tax cut is more precisely an argument for a net tax cut. This distinction is critical. As the simulations presented in Evans 1980 clearly show, a tax cut alone increases inflation. Only a tax cut accompanied by an expenditure cut (which is smaller than the tax cut) can reduce both inflation and the unemployment rate in the Evans model. Recognizing this, Senator Lloyd Bentsen of the Joint Economic Committee (U.S. Congress 1980 , p. 2) supports supply-side policies and "continues to believe that the Federal Government must put its own financial house in order."

\section{The Supply-Side Interpretation of a Tax Cut}

Based on supply-side models, some economists make very precise forecasts of what would happen if tax rates were changed. Michael Evans (1980, p. 9), the creator of the Evans model, recently told Congress that the "total increase in the labor force caused by a 1 p.p. [percentage point] reduction in the tax rate would be $0.26 \%$, or approximately 270,000 workers at the present size of the labor force." Similarly, Otto Eckstein (1980, p. 53), using another supply-side model, has estimated that

... a 1 percent rise in the real tax burden discourages 0.04 
percent of our workers from the labor force. Since 1965, the real tax burden has increased by almost 50 percent, driving 1.9 million people from the labor force according to the equation.

Policymakers sometimes treat such estimates with too much respect. For example, Senator Bentsen (U.S. Congress 1980, pp. 1-2) comments that the Eckstein supply-side model

... shows that tax policies, such as depreciation schedule adjustment, can lower the inflation rate substantially over the decade.... This new model is an important tool which will help policymakers implement the supply side policies which are being advocated by the Joint Economic Committee.

Such confidence may be misplaced. Although the new models purport to take adequate account of incentives, their forecast that tax cuts will lead to lower inflation is questionable.

The validity of the supply-side analysis can be questioned on two grounds. First, the new supply-side models have not remedied the major defects of the old models. Consequently, there is no reason for believing that they can better predict the results of changes in economic policy. Second, the empirical evidence is not adequate to support the supply-side proposition that inflation can be reduced by stimulating productivity. There seems to be little, if any, direct empirical relationship between productivity and inflation.

\section{Defects in Supply-Side Models}

Supply-side models have not corrected the fundamental problem of the traditional models, the problem that makes them incapable of quantifying the results of a previously untried tax cut or other policy change. The problem is that supply-side models, like traditional ones, are constructed so that they do not agree with the theory they are supposedly based on.

Their underlying economic theory, hardly controversial, is that economic agents optimize or, in other words, take action to obtain the goods and services they want the most, limited by only a few major constraints - their wages, prices, available technology, and time, for instance. Both supply-side and traditional models are based on this theory. According to this generally accepted theory, consumers face a single optimization problem. They must make a simultaneous decision about how to divide their time between work and leisure and how to divide their income between current consumption and saving (or future consumption). These cannot be separate decisions, because a decision to work more will lead to a higher income, and this higher income, in turn, should change their decisions about consuming and saving. Consumers solve this optimization problem - that is, they make their decisions - according to their own individual tastes and preferences, using whatever information they feel is pertinent and worth the cost of acquiring.

To be consistent with the theory of optimizing agents, an economic model must have at least two properties:

- Internal consistency. Because consumers solve a single optimization problem, the equations representing labor supply and the demand for consumption goods must be systematically related. If people decide to work less, for instance, they must make a corresponding decision to consume less. (Of course, if there is some change in the available technology or another of the constraints so that their standard of living rises, then they can work less and consume more - but this is another issue altogether.) A model is internally consistent only if the consumption and labor-supply decisions are systematically related.

- Policy consistency. Because they optimize, consumers make their decisions only after they have considered all the relevant information, such as the future values of wages and taxes. To form their expectations in a way that is consistent with the theory of optimizing agents, they cannot ignore readily available information that can determine their future well-being. Therefore, if there is a change in the government's taxing strategy, consumers must change their decisions in accordance with it. The underlying economic theory, in sum, tells us that when policy changes, the values of the coefficients in the equations representing decision rules (such as labor supply and consumption) must also change to reflect the new decisions that consumers make. (This point is discussed more fully in the appendix.)

\section{Supply-Side Models vs. Economic Theory}

Unfortunately, the supply-side models are not consistent with the theory of optimizing agents, for they do not have these two key properties. They have neither internal consistency nor policy consistency. 
The Evans model, for instance, is internally inconsistent because consumers can change how much they consume without making any change in how much they work. In other words, the equations that represent consumption and labor supply in this model can change independently of each other, as if they were unrelated. This model, in effect, divides a person's life into two unrelated halves - one that works, one that consumes. ${ }^{2}$

Similarly, the new supply-side models are not consistent with the theory of optimizing agents because the coefficients of the decision rules do not change when policy changes. A radical change in policy that is wellannounced and well-understood by the people in the relevant markets - such as a substantial tax cut, the nationalization of the oil industry, or a declaration of war-will have no immediate effect on people's expectations in these models. In some circumstances in these models, people begin to notice after a while that things have changed, and in perhaps a year or two they adjust to the changes completely. In other circumstances, they never learn and are repeatedly fooled by a continuing long-term policy. But except when the present and future policy happens to be the same as the policy in force when the models were estimated, people do not optimize and consider information that can drastically affect their well-being, even though the underlying economic theory says they must. The problem is not that they are ignorant, but that they are foolish; even when they have the information they need, they refuse to use it in an efficient way. Thus, the models assume that agents do not optimize when they form their expectations of future events, contradicting what they assume elsewhere. (For a more detailed discussion, see the appendix.)

\section{Supply-Side Models vs. the Evidence}

Although the supply-side models are not compatible with the theory that underlies them, it is still possible that they have, by chance, recommended policies that will do what they claim. That is to say, the tax cuts that supply-side advocates recommend could help fight inflation, even though this result is not supported by supply-side models. The empirical evidence, however, does not support the advocates of a tax cut without an expenditure cut.

According to supply-side advocates and their models, stimulating productivity reduces inflation. If this were the case, then lower inflation would generally tend to accompany higher productivity. The evidence I have examined, though, seems to say that lower inflation and higher productivity do not necessarily go together.

I have examined time series regressions of the logarithms of the consumer price level on the money stock and productivity (output per worker) for the United States and seven of our major trading partners: Canada, Denmark, France, Germany, Japan, Sweden, and the United Kingdom. Over the period from 1950 to 1973 (prior to the surge in oil prices which, many have argued, has adversely affected productivity growth), none of the eight countries shows a statistically significant negative elasticity of price change with respect to an increase in productivity. That is, in none of these countries has an increase in productivity been associated with a decrease in inflation. In fact, all the countries except the United States and Sweden show a statistically significant positive elasticity. This suggests that higher productivity and lower inflation do not necessarily go together. ${ }^{3}$

For the period from 1950 to 1979 (which includes the period of the large rise in oil prices), the evidence from the regression analysis adds only a bit of support to the supply-side approach to inflation. Over this period, both the United States and Sweden show statistically significant negative elasticities. Nevertheless, the other six countries show positive elasticities, some of which are significant. There is thus no strong evidence based on these regressions that higher productivity accompanies lower inflation.

The cross-section data raise still further doubts about the supply-side approach to inflation. The trends in inflation and productivity in the United States and the seven foreign countries are shown in Chart 2. The plotted observations are the trend rates of growth of consumer prices and productivity (real GNP per worker) over the post-World War II period. This

2Wallace 1980 describes the problem of unrelated decisions (or partial equilibrium) with an analogy to the standard textbook descriptions of macroeconomic models. In a typical text there is essentially one chapter for each macro relationship, and that relationship is purported to be explained by the assumptions (theory) of that particular chapter. One problem with this textbook approach is that there is no guarantee that the assumptions of different chapters, such as the one on consumption and the one on labor supply, are consistent, and hence no guarantee that there is a coherent underlying theory of the decision rules of the model.

${ }^{3}$ These simple regressions are meant to be suggestive and not definitive. The potential for simultaneous bias exists, since we have not tested for exogeneity of productivity with respect to inflation. 


\section{Chart 2}

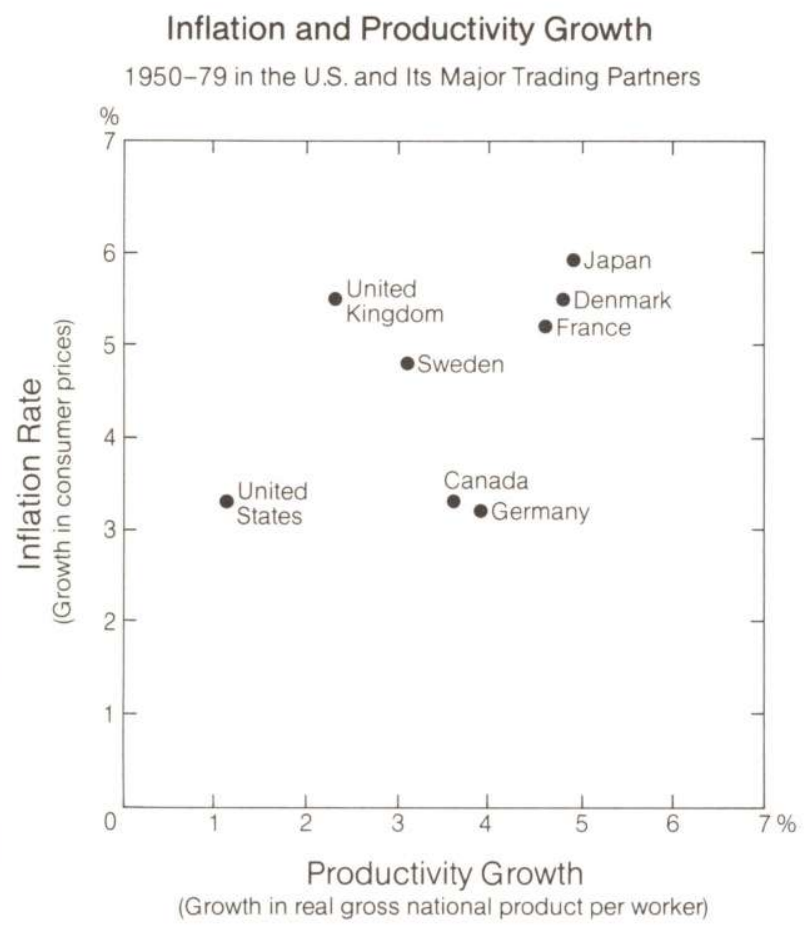

Source: International Monetary Fund

simple correlation across countries suggests that if there is any relationship between productivity growth and inflation, it is positive, not negative. ${ }^{4}$ In brief, I was again unable to find that an increase in productivity is generally associated with a decrease in inflation. ${ }^{5}$

So it is by no means clear that a government tax policy designed to induce more rapid productivity growth would really lower inflation. The evidence against the supply-side view is certainly strong enough to make us question the validity of supply-side prescriptions.

\section{Better Models and Methods}

Both economic theory and empirical observations suggest that tax cuts which are rationalized by the new supply-side models are by no means a certain way to reduce inflation, although tax cuts may be warranted for other reasons. As this paper demonstrates, these models cannot be used to assess the effects of a tax cut or any other new policy, because they are not stable when policy changes. Although they can proviide reasonably accurate forecasts when policy is constant, they simply cannot deal with a change in policy in a way that is consistent with the theory they are based on. Like the traditional models, therefore, they cannot be trusted to tell us how the economy will react to a tax cut, not even approximately. As this paper also demonstrates, the relationship between productivity and inflation, which the supply-side advocates hope to exploit, is highly uncertain and is very likely influenced by factors - both cyclical and secular - other than tax policy. (See Denison 1979.) Because of this, one must be suspect of the notion that there is a direct negative relationship between productivity and inflation.

Even to begin to comprehend how the economy works, we need economic models which are capable of analyzing alternative economic policies, models that remain stable when policy changes. Although considering such models is beyond the scope of this paper, it is worth noting that such models will require an entirely new approach, not merely the simple alterations of traditional models that have resulted in supply-side models. One strategy for building economic models

${ }^{4}$ Chart 2, however, does not represent as strong a case against supply-side models as the time series regressions, since it does not take account of differences across countries in such things as monetary policies.

5In fact, inflation is higher in some countries when their rate of increase in productivity is higher. Yet it is commonly held that for a given rate of wage increase, an increase in productivity will lead to a slowdown in inflation, since firms could maintain their presumably fixed profit-margin mark-ups over labor costs at lower prices. Should Chart 2 then be dismissed as simply recording a spurious correlation? Not necessarily.

Even under the theory that wages are the predominant cause of inflation, this correlation can be explained. The actual inflation rate is affected by the growth in nominal wage rates which is affected by expectations of both productivity growth and inflation. If workers expect their output to increase, they will attempt to bargain for at least part, if not all, of this output increase. It makes no sense to talk of a given wage increase when productivity is expected to change. Furthermore, as implied by the discussion in the appendix, the relationship between wages and inflation could change when there is a new expected productivity path. Inflation could thus increase even when productivity is increasing.

The positive correlation between productivity and inflation can also be explained under the alternative theory that inflation is determined by monetary and fiscal policy while output is determined largely by productivity. If monetary and fiscal policies are fixed, a spurt in the growth of productivity (caused, for example, by a major technological change) would likely produce price levels lower than what they would otherwise have been. Under these conditions, too, output would likely increase. However, if the higher productivity growth is induced by some change in monetary or fiscal policy, then the effects are much harder to determine. It is possible that the inflation-raising aspects of the policy stimulus would swamp the inflation-lowering aspects of the increase in productivity. 
that is consistent with the underlying economic theory is provided by Lucas and Sargent (forthcoming). ${ }^{6}$ Unfortunately, it is likely to be some time before this strategy produces models that can be used for meaningful policy simulations.

Until meaningful macroeconomic models are available for policy simulations, policymakers will have to use more modest tools. They can rely, for instance, on some microeconomic models which do not have the serious defects of the supply-side and traditional models. (Such models are discussed in detail in KarekenWallace 1980.) These micro models, however, may not encourage cutting taxes in order to reduce inflation. Some, in fact, suggest that the larger budget deficits created by cutting taxes are themselves inflationary. (See Miller 1980 and Miller-Struthers 1980.) In addition, policymakers can supplement these models by examining previous experience, not only from recent U.S. history, but from other times and places. One important study by Sargent (1980), for example, shows that four countries in this century stopped inflations that were much more severe than our own, not by boosting productivity, but by stopping the growth of unbacked government debt. Such tools are more difficult to use than macro models because they do not produce policy simulations, but at present they are the best tools we have.

6See also Miller-Rolnick 1980. Meese (1980) has recently argued that although the data do not strongly support the theoretical restrictions implied by rational expectations, the methodology described in the Lucas-Sargent (forthcoming) volume "may prove to be the most useful approach to employ in future work" (p. 153). 


\section{Technical Appendix Existing models cannot predict results of policy interventions}

No current macroeconomic models, neither traditional nor supply-side, can correctly analyze the results of a change in government policy because the structure of these models is incapable of dealing with such policy interventions. Perhaps the most crucial reason that these models are inadequate is that their depiction of expectations is irrational and inconsistent.

Expectations of the future (such as future inflation) are important variables in the decision rules of agents that underlie economic models. But the existing models typically treat the agents as acting irrationally in the sense that their expectations of the future depend in a fixed way only upon events in the past. Thus, by the very nature of their construction, the models prohibit agents from acting in their own best interest - and systematically altering the way events of the past are incorporated into their decision rules when there is a change in government policy.

Model builders are aware of the irrational behavior that they are designing into their models, but they tend to believe that a weighted average of the past allows for behavior that is plausible because workers eventually catch on to the actual inflationary process. For example, Eckstein $(1980$, p. 11) argues that expectations about the future rate of inflation are formed by "a gradual learning process rather than a quick response to policies or other particular events. The theory [of the DRI model] is consistent with a weak form of the rational expectations viewpoint that price expectations are free of bias in the long run, but it is inconsistent with the stronger viewpoint that these price expectations are formed quickly from particular policy announcements or exogenous events."

Unfortunately, there are at least two serious problems with this view of expectations formation. First of all, it assumes that if the lag weights sum to unity, then expectations are formed rationally, at least in the long run. But the theory of rational expectations says nothing a priori about the sum of the lag weights. The true sum is determined by the process actually generating inflation, and that sum is what should rationally be expected. (See Sargent 1976, pp. 3-6.) With Eckstein's equation there are some policy changes that people would never catch on to, in any length of time.

Secondly, since actual inflation rates in these econometric models are determined largely by expected inflation rates, the assumption of a fixed (and long) lag structure on past inflation rates automatically imposes a constraint on the impact of any policy action on the actual inflation rate. The typical model thus predicts that inflation is slow to adjust to policy changes. According to the DRI study (Eckstein 1980, p. 37), if the government announced today that it would follow demand-management policies which maintained the unemployment rate at about 8.5 percent from now through 1985 , then the core inflation rate would be reduced by only about one percentage point from its current 9.1 percent to 7.8 percent in 1985. To take such a statement seriously, it is necessary to assume that economic agents would act in the same way under the new policy regime as they did under previous regimes when it was unacceptable to maintain an 8.5 percent unemployment rate over an extended period of time. But widely accepted economic theory tells us that economic decision rules would likely change in the face of a change in economic policy.

Why should decision rules depend on economic policy? In economic theory consumers are viewed as facing a single optimization problem. They must make a simultaneous decision about how to divide their time between work and leisure and how to divide their income between current consumption and saving (future consumption). This decision is made according to their tastes and certain constraints, including their perception about certain future events. The solution to this optimization problem is a pair of decision rules, which describes how the current work and consumption decisions respond to economic stimuli.

Drawing on the work of Lucas and Rapping (1969), Sargent (1979, p. 370) writes the consumer decision rules as

$$
\begin{array}{r}
\ln N_{t}=\beta_{0}+\beta_{1} \ln w_{t}+\beta_{1} \ln \tau_{t}-\beta_{2} E\left(\ln w_{t+1} / I_{t}\right) \\
-\beta_{2} E\left(\ln \tau_{t+1} / I_{t}\right)
\end{array}
$$

and

$$
\begin{array}{r}
\ln C_{t}=\beta_{0}^{\prime}+\beta_{1}^{\prime} \ln w_{t}+\beta_{1}^{\prime} \ln \tau_{t}-\beta_{2}^{\prime} E\left(\ln w_{t+1} / I_{t}\right) \\
-\beta_{2}^{\prime} E\left(\ln \tau_{t+1} / I_{t}\right)
\end{array}
$$

where $N_{t}$ is the quantity of labor supplied during time period $t$ (the present), $w$ is the real wage rate, $\tau$ is the after-tax rate $(1-$ tax rate) on wage income, $C$ is the amount of real consumption, $E\left(\cdot / I_{t}\right)$ denotes the expected value of the relevant variable conditional on information $\left(I_{t}\right)$ available to 
the consumer at time period $t$, and $\ln$ denotes the natural logarithm of the associated variable. (Sargent writes these decision rules in a more general form, using an infinite rather than a two-period horizon and including some other variables. Except for tax-rate considerations and the method of expectations formation, my setup closely approximates the empirical version of the Lucas-Rapping model.)

Since the decisions come from the solution to the same optimization problem, the parameters $\beta_{i}$ and $\beta_{i}^{\prime}$ that determine the current $N$ and $C$ decisions are related. They will be related by the parameters that determine the preferences of the consumer and by whatever constraints the consumer faces.

Now according to decision rules (1) and (2), in order to make a decision about present $N$ and $C$, consumers will consider not only present $w$ and $\tau$ (which we assume are known at the time of the decision), but also the expected future $w$ and $\tau$. They must make a prediction in a way that is consistent with the original assumption of the optimizing behavior of the agents. Since the future is important to these agents, the evolution of these variables is a relevant constraint on their ultimate decision rules.

Suppose that, during the sample period over which these decision rules are to be estimated, the evolutionary processes could be described by

$$
\ln w_{t}=\eta_{1} \ln w_{t-1}+\eta_{2} \ln w_{t-2}+\eta
$$

and

$$
\ln \tau_{t}=\psi_{1} \ln \tau_{t-1}+\psi_{2} \ln \tau_{t-2}+\psi
$$

where $\eta$ and $\psi$ are independent random variables with zero means and constant variances. Then

$$
E\left(\ln w_{t+1} / I_{t}\right)=\eta_{1} \ln w_{t}+\eta_{2} \ln w_{t-1}
$$

and

$$
E\left(\ln \tau_{t+1} / I_{t}\right)=\psi_{1} \ln \tau_{t}+\psi_{2} \ln \tau_{t-1} .
$$

Substituting (5) and (6) into (1) yields

$$
\begin{aligned}
\ln N_{t}=\left(\beta_{0}\right) & +\left(\beta_{1}-\beta_{2} \eta_{1}\right) \ln w_{t}-\left(\beta_{2} \eta_{2}\right) \ln w_{t-1} \\
& +\left(\beta_{1}-\beta_{2} \psi_{1}\right) \ln \tau_{t}-\left(\beta_{2} \psi_{2}\right) \ln \tau_{t-1} .
\end{aligned}
$$

Similarly,

$$
\begin{aligned}
\ln C_{t}=\left(\beta_{0}^{\prime}\right) & +\left(\beta_{1}^{\prime}-\beta_{2}^{\prime} \eta_{1}\right) \ln w_{t}-\left(\beta_{2}^{\prime} \eta_{2}\right) \ln w_{t-1} \\
& +\left(\beta_{1}^{\prime}-\beta_{2}^{\prime} \psi_{1}\right) \ln \tau_{t}-\left(\beta_{2}^{\prime} \psi_{2}\right) \ln \tau_{t-1} .
\end{aligned}
$$

When estimated statistically, these equations would appear as

$$
\ln N_{t}=a_{0}+a_{1} \ln w_{t}+a_{2} \ln w_{t-1}+a_{3} \ln \tau_{t}+a_{4} \ln \tau_{t-1}
$$

and

$$
\ln C_{t}=b_{0}+b_{1} \ln w_{t}+b_{2} \ln w_{t-1}+b_{3} \ln \tau_{t}+b_{4} \ln \tau_{t-1} .
$$

The equations represent the decision rules of an optimizing consumer where (9) may be viewed as a labor-supply equation and (10) as a demand-for-consumption-goods equation.

Observe that the coefficients of the two equations, the $a_{i}$ 's and the $b_{i}$ 's, are related. They are related because both $\beta_{i}$ and $\beta_{i}^{\prime}$ depend on the same optimization decision; when one changes, the other must therefore change. The coefficients of the two equations are also related by the $\eta_{i}$ 's and the $\psi_{i}$ 's which appear in all but the first term of the equations. The $\eta_{i}$ 's are determinants of the evolutionary process of the real-wage variable, and the $\psi_{i}$ 's are determinants of the evolutionary process of the after-tax rate - if either of these evolutionary processes changes, both decision rules, not just one, will thus change. The fact that these equations are sensitive to policy changes is extremely important. Not only do the values of the after-tax rate enter the decision rules, but so do the parameters that determine the evolution of the rate. If there is a change in taxing strategy, say in $\psi_{1}$, then there is a change in the values of the parameters in both equations. The structure of the above equations thus responds to a change in policy, although an isolated tax rate that arises simply because of a nonzero observation of $\psi$ does not affect the structure.

Although supply-side equations are of the form of (9) and (10), they don't capture these crucial points - in these equations the $a_{i}$ 's and $b_{i}$ 's are not related and the coefficients do not change when policy changes. To illustrate these defects of the supply-side models, consider a labor-supply equation from the Evans model. The actual form of this equation is

$$
L_{t}=c_{0}+c_{1}(w \tau)_{t-1}+c_{2} u_{t-1}+c_{3} I_{t-1}+c_{4} I_{t-5}
$$

where $L$ is the labor force participation rate for females ages 25 to $54 ; w$ is a measure of the real wage; $\tau$ is a measure of the after-tax rate; $u$ is the change in the total unemployment rate; and $I$ is a measure of the rate of inflation. The equation was estimated on a quarterly basis over the sample period from 1961 to 1978.

This equation attempts to quantify the work-incentive effects of tax policy [described in equation (4)] by including the tax rate explicitly as an explanatory variable on the righthand side of the equation. Note, however, that it is only the tax rate itself that is included and not the parameters that describe the evolution of the tax rate. As long as these parameters are not changing over time, there is no logical problem in treating them as being subsumed into the constant $c_{i}$ parameters. However, these parameters can change over time. It is precisely the stability (or invariance) of these parameters over time that is questioned by the equations I have presented. 
It is possible to examine this invariance statistically. One common statistical procedure for testing for invariance is the Chow test. The idea of this test is to break the total sample period into subperiods and check whether the estimated parameters of the decision rules are very different for the various sample periods. The Chow test indicates that there has, in fact, been a structural change in decision rule (11).*

The parameters describing the participation-rate decision rule (11) do not appear to be stable and hence cannot be expected to provide meaningful predictions of the effects of a change in tax policy. Thus, we have both logical as well as empirical reasons for rejecting the policy analysis of current macroeconomic models until the builders can establish that the structure of their models is capable of dealing with policy interventions.

\section{References}

Boskin, Michael J. 1978. Taxation, saving, and the rate of interest. Journal of Political Economy 86 (April, pt. 2): S3-S27.

Denison, Edward F. 1979. Explanations of declining productivity growth. Survey of Current Business 59 (August): 1-24.

Eckstein, Otto. 1980. Tax policy and core inflation. A study prepared for the U.S Joint Economic Committee, 96th Cong., 2d sess. Washington, D.C.

Evans, Michael K. 1980. New developments in econometric modeling: supplyside economics. Testimony for the U.S. Joint Economic Committee, 96th Cong., 2d sess., May 21. Processed. Evans Economics, Inc.

Evans Economics, Inc. 1980. Documentation of macroeconomic model constructed for the U.S. Senate Finance Committee. Processed.

Kareken, John H., and Wallace, Neil, eds. 1980. Models of monetary economies. Proceedings and contributions from participants of a December 1978 conference sponsored by the Federal Reserve Bank of Minneapolis. Minneapolis: Federal Reserve Bank of Minneapolis.

Lucas, Robert E., Jr., and Rapping, Leonard A. 1969. Real wages, employment, and inflation. Journal of Political Economy 77 (September/October): $721-54$

Lucas, Robert E., Jr., and Sargent, Thomas J., eds. Forthcoming. Rational expectations and econometric practice. Minneapolis: University of Minnesota Press.

McCarthy, Michael D. 1972. The Wharton quarterly econometric forecasting model MARK III. Department of Economics Studies in Quantitative Economics 6. Philadelphia: University of Pennsylvania, Wharton School of Finance and Commerce.

Meese, Richard. 1980. Dynamic factor demand schedules for labor and capital under rational expectations. Journal of Econometrics 14 (September): 141-58.

Miller, Preston J. 1980. Deficit policies, deficit fallacies. Federal Reserve Bank of Minneapolis Quarterly Review 4 (Summer): 2-4.

Miller, Preston J., and Rolnick, Arthur J. 1980. The CBO's policy analysis: an unquestionable misuse of a questionable theory. Journal of Monetary Economics 6 (April): 171-98.

Miller, Preston J., and Struthers, Alan, Jr. 1980. The tax-cut illusion. In Federal Reserve Bank of Minneapolis 1979 Annual Report, pp. 1-9. Minneapolis: Federal Reserve Bank of Minneapolis.

Sargent, Thomas J. 1976. Testing for neutrality and rationality. In Rational expectations and the theory of economic policy, part II: arguments and evidence, Research Department Studies in Monetary Economics 3:1-21. Minneapolis: Federal Reserve Bank of Minneapolis.

1979. Macroeconomic theory. New York: Academic Press.

1980. The ends of four big inflations. Research Department Working Paper 158. Minneapolis: Federal Reserve Bank of Minneapolis.

U.S. Congress. Joint Economic Committee. 1980. Plugging in the supply side. Report on the January 1980 Economic Report of the President. 96th Cong., 2d sess. Sen. Rept. 96-618. Washington, D.C.

Wallace, Neil. 1980. Discussion of the Meyer-Rasche and Taylor papers. In Stabilization policies: lessons from the ' 70 s and implications for the ' $80 \mathrm{~s}$, pp. 103-112. Proceedings of a conference cosponsored by the Center for the Study of American Business and the Federal Reserve Bank of St. Louis. St. Louis, Mo.: Washington University, Center for the Study of American Business. 